\title{
Evidence for preferences of Italian patients for physician attire
}

\author{
This article was published in the following Dove Press journal: \\ Patient Preference and Adherence \\ 24 April 2012 \\ Number of times this article has been viewed
}

\author{
Giovanni Sotgiu' \\ Paolo Nieddu ${ }^{2}$ \\ Laura Mameli ${ }^{2}$ \\ Enrico Sorrentino ${ }^{2}$ \\ Pietro Pirina ${ }^{3}$ \\ Alberto Porcu ${ }^{4}$ \\ Stefano Madeddu' \\ Manuela Idini' \\ Maddalena Di Martino' \\ Giuseppe Delitala ${ }^{2}$ \\ Ida Mura' \\ Maria Pina Dore ${ }^{2}$ \\ 'Epidemiology and Medical \\ Statistics Unit, Department of \\ Biomedical Sciences, ${ }^{2}$ Clinica Medica, \\ ${ }^{3}$ Pneumologia, ${ }^{4}$ Chirurgia dell'Obesità, \\ University of Sassari, Sassari, Italy
}

Background: The relationship between patient and physician is a complex interaction that includes multiple factors. The objective of this study was to explore Italian patients' preferences regarding physician appearance.

Methods: A questionnaire was developed to survey patients in different medical and surgical settings; each subject was asked to choose one picture of either a male or female physician from a selection of different attires (professional, casual, surgical scrubs, trendy, and careless). Patients were also surveyed about issues such as the presence of a name tag, hair length, trousers on women, amount of makeup, presence of tattoos, and body piercing. Statistical analysis was performed using a Chi-square test.

Results: A total of 765 questionnaires (534 completed from patients waiting for an internal medicine visit and 231 for other subspecialties) were completed. The majority (45\%) of patients preferred the gastroenterologist to wear a surgical scrub with a white coat. For the other specialists, patients accepted either scrubs or formal dress under a white coat $(P \leq 0.05)$, with a name tag. Trendy attire was preferred by nine patients $(1.1 \%)$. The entire sample judged it inappropriate for clinicians to have long hair, visible tattoos, body piercing, and, for women, to wear trousers and use excessive makeup.

Conclusion: This is the first study conducted in Italy regarding physician attire. As in other Western countries, Italian patients favor physicians in professional attire with a white coat. Wearing professional dress is part of "etiquette based medicine" and may favorably influence clinician-patient relationships and patient compliance.

Keywords: physician attire, appearance, etiquette medicine

\section{Introduction}

The human relationship between the patient and the physician is the basis for care, as highlighted by healers since Hippocrates' time. This psychosocial interplay can be influenced by numerous variables (for instance, culture, religion, age, and education). ${ }^{1-4}$ A patient develops opinions and thus trust and confidence based on the physician's empathy and verbal and nonverbal communication, including the physician's dress style. ${ }^{2,5,6}$ Since ancient times the carelessly dressed physician has been perceived as unqualified and insensible by numerous patients. ${ }^{2}$

In Western countries the white coat has been deemed the icon of the physician for more than a century. ${ }^{7-12}$ In past years studies carried out in the US and in England highlighted the preference that patients displayed for conventional appearance, varying from white coats to formal suits, short hair and ties for men, and skirts and blouses for women; casual items like sports shoes and jeans did not suggest courteousness or professionalism, causing mistrust of physicians. ${ }^{2-16}$

\author{
Istituto di Clinica Medica, \\ Universita di Sassari, Viale San Pietro, \\ 8,07100 Sassari, Italy \\ Tel +39079 229886 \\ Fax +39079 228207 \\ Email mpdore@uniss.it
}

submit your manuscript | www.dovepress.com

Dovepress

http://dx.doi.org// 0.21 47/PPA.S29587
(C) 2012 Sotgiu et al, publisher and licensee Dove Medical Press Ltd. This is an Open Access article which permits unrestricted noncommercial use, provided the original work is properly cited. 
In this era of modern and consumerist medicine due to negative media impact, doctors are experiencing stress, depression, and anxiety, fuelled by the increasing demands for health services, and a lack of resources to support them.

The use of a white coat and formal dress has been recently questioned by some categories of medical doctors (mainly pediatricians and psychiatrists in the United Kingdom and Denmark), in order to avoid a nonverbal barrier to patient interaction and a paternalistic patient-physician relationship, aiming for a more equal one. ${ }^{17,18}$

Different surveys confirmed this "modern" point of view, without being prejudiced by the age of the respondents. A study performed among adolescents, with the aim of evaluating their opinion on physicians' dress style ranging from informal to formal, evidenced no difference in patient attitudes toward their physician. ${ }^{19}$ In other epidemiological investigations, most of the adult patients claimed that the attire of the physician did not influence their choice of family physician or satisfaction. ${ }^{20-22}$

The aim of the present survey was to evaluate preferences of Italian patients attending internal medicine (more specifically gastroenterology) and surgical outpatient settings in the University of Sassari, Italy, toward their physician's professional appearance.

\section{Material and methods Patients}

Subjects attending medical (gastroenterology) and surgical (ENT [ear, nose, and throat], orthopedic, urology, general surgery) departments at the University of Sassari, Italy, were invited to participate in this study; for those who accepted, a questionnaire was administered to measure their preferences for the sartorial and physical characteristics of physicians. Socio-demographic, epidemiological, and clinical information was collected for each patient.

The accuracy (ie, reliability and validity) of the survey was tested in a pilot study where a small group of medical doctors assessed all the items listed in the questionnaire; moreover, the questionnaire also included a section with photographs of physicians (one set with male and one set with female) attired in the following five styles of dress shown in Figures 1 and 2:

1. professional attire (neck tie and white coat for male or skirt and white coat for female)

2. surgical scrubs (for both male and female)

3. casual attire (jeans and T-shirt for both male and female)
4. trendy attire (jeans, sport shoes, and T-shirt for both male and female)

5. careless attire (jeans, T-shirt, body piercing, and tattoos for both male and female)

They were worn by two research assistants, who, as far as possible, posed more or less in the same way for all the pictures. Relatively young models were chosen because older models dressed informally would seem a little unlikely to patients.

Individuals had to report on their willingness to share their health issues with the physicians in each of the five previously-mentioned pictures: "Which doctor would you feel happiest about seeing for the first consultation?", and to rate how strongly they felt about the value of specific items of their physician's dress on a three-point scale: "I like it", "I don't like it", or "I don't know". There were only closed questions without any possibilities for comments.

For both sexes, items included: name tag, buttoned or unbuttoned white coat, dress with and without jacket, formal or casual dress, open shirt, fashionable clothes, scrub suit, visible stethoscope, dress shoes, sport shoes, clogs, sandals, without socks, long or short hair, overweight, cleaned teeth, long or short nails, tattoos, and body piercing. More specifically for male physicians, patients were asked about cleanshaveness, well-groomed or long beard, and use of cologne; and for female physicians, characteristics were braided or colored hair, use of perfume, long nails (without or with nail polish), light or heavy makeup, and jewelry.

\section{Statistical analysis}

A descriptive cross-sectional epidemiological design was adopted in order to obtain only a point evaluation. No attempt was made to evaluate whether individuals would give similar responses if asked to repeat the survey at a later date. Consecutive outpatients who accepted to participate were enrolled.

The sample size of 750 respondents was estimated to ensure high $(>80 \%)$ statistical power so as to detect significant differences among prespecified groups of participants.

Outpatients completed the questionnaire while in the waiting room of the outpatient setting. It was preferably distributed by nurses and collected before their physician consultation to avoid systematic bias. Participation was voluntary and anonymity was maintained.

Categorical variables were compared by Chi-squared test; the Student's $t$-test was used for continuous variables, and its nonparametric version (Wilcoxon-Mann-Whitney test) was used when appropriate. Logistic regression analysis was 


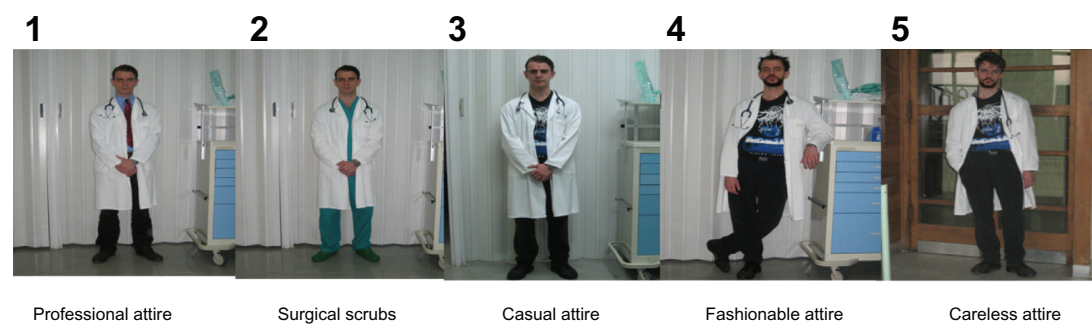

Figure I Pictures of male physicians included in the questionnaire in the following five styles of dress show: (I) professional attire; (2) surgical scrubs; (3) casual attire; (4) trendy attire; (5) careless attire.

performed in order to evaluate the odds ratios (ORs) associated with pictures, comparing patients who chose a picture versus those who did not, respectively. A $P$-value of $\leq 0.05$ was considered statistically significant. Data were collected on standardized e-forms and analyzed using Stata 9.0 (StataCorp, Stata Statistical Software Release 9, College Station, TX).

\section{Results}

The questionnaires were distributed from November 2008 to September 2009. A total of 765/781 (98\%) questionnaires (534 completed from patients waiting for an internal medicine visit and 231 for other subspecialties), were collected for analysis.

Sociodemographic characteristics of the respondents are described in Table 1. Patients included 508 in the gastroenterology unit (73.4\%) and 200 female patients (67.1\%; $P=0.04)$ in other medical and surgical departments. Individuals attending the gastroenterology unit were younger than those attending other departments (mean age \pm standard deviation: $40.4 \pm 14.6$ versus $48.7 \pm 17.9$ years, respectively; $P<0.0001)$. Proportions of patients with a higher educational level were significantly more represented in the gastroenterology unit group (high school: $41.2 \%$ versus $26.2 \%, P=0.0001$; university: $24.6 \%$ versus $15.9 \%, P=0.008$ ). No statistical significant differences were detected across different occupations (housewife, employee, student), between patients in gastroenterology, and those in non-gastroenterology groups.
The majority of the respondents chose picture number 2 with physicians wearing surgical scrubs for male (47\%) and female $(43.7 \%)$, followed by picture number 1 professional attire for male (30.7\%) and female $(26.8 \%)$ physicians, and picture number 3 casual attire for male (18.6\%) and female (23.8\%) physicians; only a few subjects $(<6 \%)$ showed preference toward modern attire (ie, pictures number 4 and 5 ; Table 2).

The finding of a preferred traditional medical doctor was confirmed by the higher proportions of patients who liked those traditional images investigated by the survey tool (Figure 3).

Several statistically significant differences were shown taking into account confounding variables, such as gender, age ( $<40$ and $\geq 40$ years) and department of admission (gastroenterology or surgical department; Figures 4 and 5, Table 3).

People aged $<40$ years chose picture number $2(>50 \%$ for male and female physicians) more frequently than those aged $\geq 40$ years $(P<0.001)$; older subjects preferred professional attire $(P<0.001)$. The proportion of those aged $<40$ years who chose modern pictures (ie, picture number 4 and 5 ) was very low $(<10 \%)$, but significantly higher than that identified in the group of people aged $\geq 40$ years (Figure 4 ).

Female patients preferred surgical scrubs to professional attire for male $(50.7 \%)$ and female $(47.4 \%, P<0.001)$ physicians. Men surveyed chose professional attire more

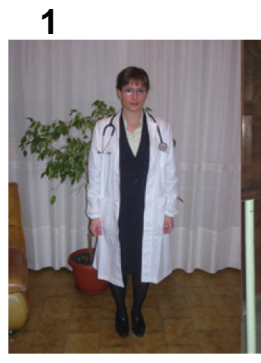

Professional attire 2 3 4 5

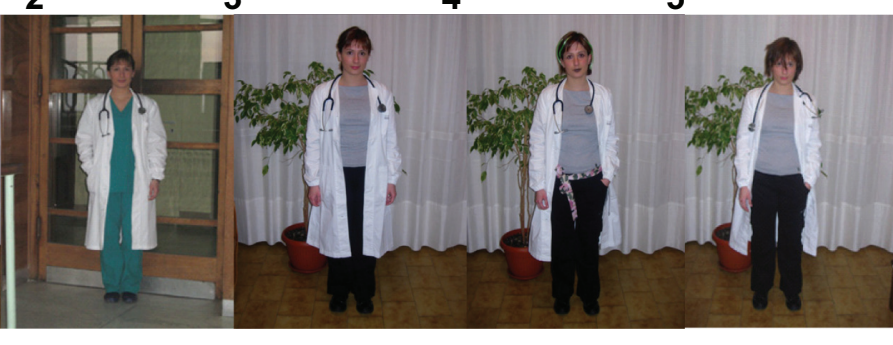

Surgical scrubs

Casual attire

Fashionable attire Careless attire

Figure 2 Pictures of female physicians included in the questionnaire in the following five styles of dress show: (1) professional attire; (2) surgical scrubs; (3) casual attire; (4) trendy attire; (5) careless attire. 
Table I Sociodemographic characteristics of 765 patients answering the questionnaires in Sassari University Hospital, Italy

\begin{tabular}{llll}
\hline Variables & GE group & Others & P-value \\
\hline Age, mean (SD) years & $40.4(14.6)$ & $48.7(17.9)$ & $<0.000$ I \\
$\begin{array}{l}\text { Gender, female (\%) } \\
\text { Education (\%) }\end{array}$ & $508(73.4)$ & $200(67.1)$ & 0.04 \\
$\quad$ & & \\
$\quad$ Middle school & $1720(25.8)$ & $102(35.2)$ & 0.008 \\
$\quad$ High school & $275(4 \mid .2)$ & $76(26.2)$ & 0.000 I \\
$\quad$ University & $164(24.6)$ & $46(15.9)$ & 0.008 \\
Occupation (\%) & & & \\
$\quad$ Housewife & $107(18.3)$ & $64(23.4)$ & 0.1 \\
$\quad$ Employee & $79(13.5)$ & $23(8.4)$ & 0.05 \\
Student & $70(I 2)$ & $23(8.4)$ & 0.14 \\
\hline
\end{tabular}

Abbreviations: GE, gastroenterology; SD, standard deviation.

frequently than women for both male (38.5 versus 27.4 , $P=0.001)$ and female (31.9 versus $24.7, P=0.03$ ) medical doctors. No statistically significant differences were found for pictures number 3, 4, and 5 for both male and female physicians (Figure 5).

Interestingly, contrary to our expectations, Table $2 \mathrm{dem}$ onstrates that profile number 2 is chosen more frequently in the medical departments while professional attire is selected in surgical departments, for both male (50.9\% and 36.3\%) and female (49.3\% and $37.8 \%)$ physicians, respectively.

Logistic regression analysis confirmed the statistically significant results described above, quantifying the effect of some covariates (age, gender, and educational level). In the uni- and multivariate analyses it was shown that to be male and aged $\geq 40$ years increased the odds of choosing picture number 1 , for both male and female physicians, while having a higher educational level (high school and university) decreased that probability (ORs were $<0.57$ and $<0.6$ in the uni- and multivariate analysis, respectively; Table 3 ). On the other hand, to be male and aged $\geq 40$ years

Table 2 Preferences of patients for physical characteristics of physicians

\begin{tabular}{llll}
\hline & GE group & Others & P-value \\
\hline Female pictures (\%) & $\mathbf{n}=\mathbf{6 2 9}$ & $\mathbf{n}=\mathbf{2 7 8}$ & \\
\hline & $138(21.9)$ & $105(37.8)$ & $<0.000 \mathrm{I}$ \\
2 & $310(49.3)$ & $86(30.9)$ & $<0.000 \mathrm{I}$ \\
3 & $155(24.6)$ & $61(21.9)$ & 0.38 \\
4 & $17(2.7)$ & $22(7.9)$ & 0.0004 \\
5 & $9(1.4)$ & $4(1.4)$ & - \\
Male pictures (\%) & $\mathbf{n}=61 \mathbf{5}$ & $\mathbf{n}=\mathbf{2 7 3}$ & \\
I & $174(28.3)$ & $99(36.3)$ & 0.02 \\
2 & $313(50.9)$ & $104(38.1)$ & 0.0004 \\
3 & $107(17.4)$ & $58(21.2)$ & 0.18 \\
4 & $15(2.4)$ & $7(2.6)$ & 0.86 \\
5 & $6(1)$ & $5(I .8)$ & 0.32 \\
\hline
\end{tabular}

Abbreviation: GE, gastroenterology. significantly decreased the odds of choosing picture number 2 , for both male and female physicians, while having a higher educational level (high school and university) significantly increased the odds for surgical scrubs (ORs $>1.5$ in uni- and multivariate analysis, respectively).

\section{Discussion}

This is the first study conducted in Italy, and one of the few in Western Europe, regarding physician attire. It confirmed results of previous surveys performed in other countries: respondents prefer formal attire with a white coat at the beginning of a medical or a surgical consultation with an unknown, male or female, medical doctor in outpatient settings ( $>25 \%$ of the total sample). ${ }^{2-16,23}$ Casual or semiformal attire was found to be least preferred, in contrast to findings described by other authors. ${ }^{24}$

However, our findings indicate that surgical scrubs could be another relevant option ( $>40 \%$ of the total sample), with statistically significant differences according to explanatory variables such as age, gender, and education; on the other hand, we did not identify any important dissimilarities stratifying by specialty or disease. Similar results for surgical scrubs were obtained in a United Kingdom survey where patients explained that their choices were linked to the ideas of professionalism and trust. ${ }^{25}$

It could be inferred that this kind of choice (surgical scrubs and professional attire, ie, pictures 1 and 2 in the survey tool), might be associated with greater patient trust and confidence before beginning an interpersonal medical doctor-patient interaction, as highlighted by other authors in a variety of settings. ${ }^{2-16}$ Interestingly, the percentage of young individuals ( $<40$ years) who chose modern attire was unexpectedly very low, while it was significantly higher for traditional dress.

A symbol is an element of communication representing an idea, an object, or a quality; it is a sign capable of evoking a relationship between a concrete object and a mental image. Normally, the relationship between the symbol and that which it represents is conventional and subjective, strongly influenced by the fact that meaning is a shared social phenomenon. It is therefore not unreasonable that patients associate professionalism and authority with a model of formal physician attire (including a white coat), identifying in this a competent figure that can ably assist them: a professional who will treat patients with the same respect that they display for their own person.

As shown in the tables which contain the various characteristics, the model image preferred by patients is traditional: formal dress or scrubs, name tag, hair 


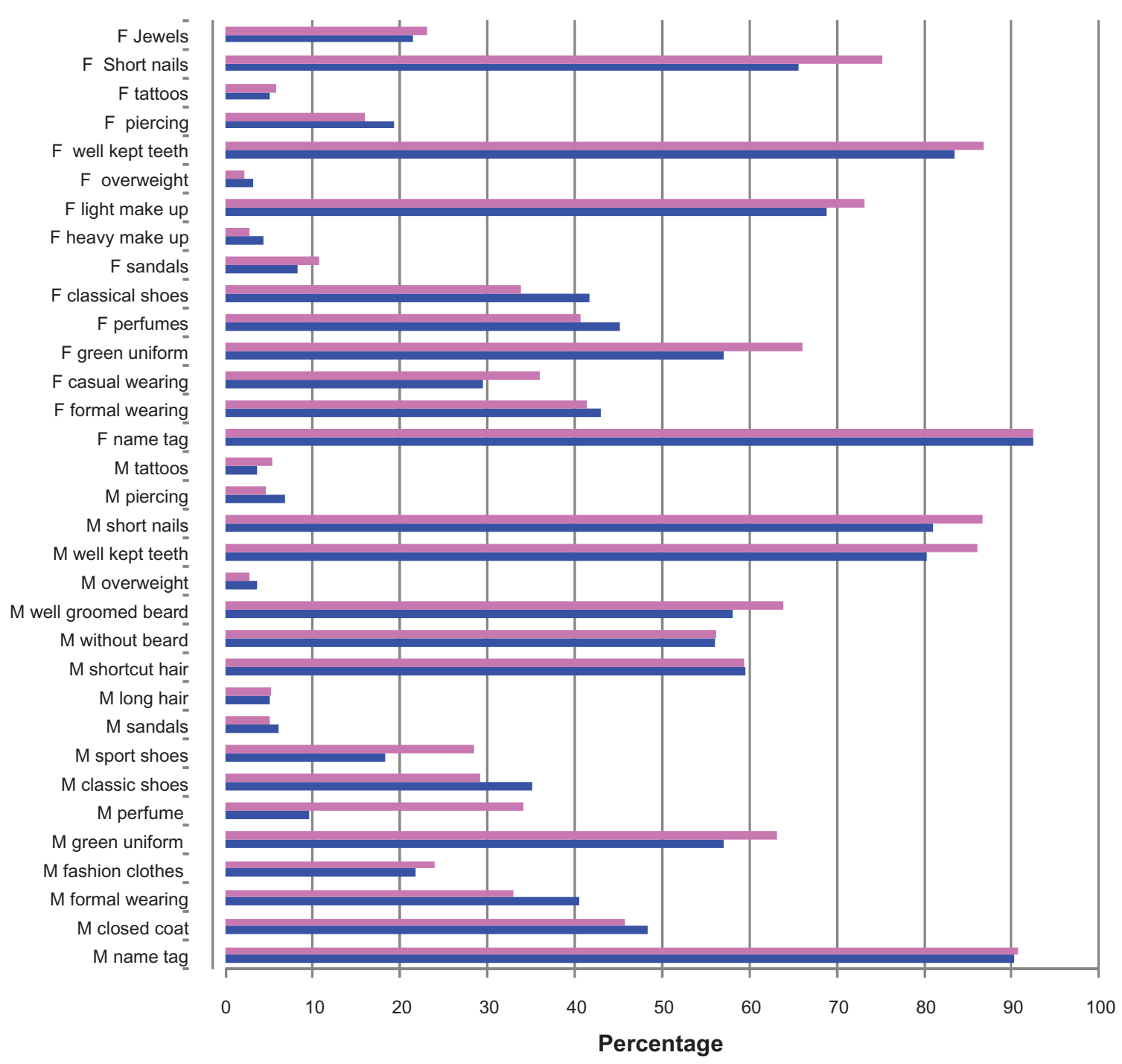

Figure 3 Preferences of Italian patients toward their physician's professional appearance.

Abbreviations: $F$, female; $M$, male.

gathered up or short, trimmed nails, absence of jewelry or tattoos. Patients not only indicated their preference for a certain style of dress, but underlined those details which suggest an attention to personal hygiene and body care as demonstrated by the fact they prefer clinicians who are not overweight. Long nails, unbound disordered hair, casual attire, and the relatively recent tendency to display tattoos, are all characteristics that patients do not appreciate in their physician.

First impressions transmit a powerful message. While an individual's perceptions should be based on what a person knows or is, rather than how he or she looks, most people tend to form (on the basis of age, gender, religion, etc), an opinion about another person when they first meet and it usually relates to the other's appearance. A well-dressed appearance tends to convey a higher level of knowledge and sincere interest and trust in advancement; on the other hand, a disheveled physician gives the impression of being a disinterested performer. ${ }^{26}$

The questions in the tool do not allow linking of the results to past experiences of the respondents, or to the influence of fictitious medical television programs. Older patients were significantly more likely to prefer classical attire with a white coat than those aged $<40$ years more oriented to a trendy profile probably because of television media influence.

It is clear that the proportion of the respondents who prefer casual/informal and/or disheveled physicians is very low, independently of confounding covariates like age or gender. Patients in the current settings found physician-identifying items preferable for their medical doctors and less formal attire undesirable; the expectations were similar for both male 

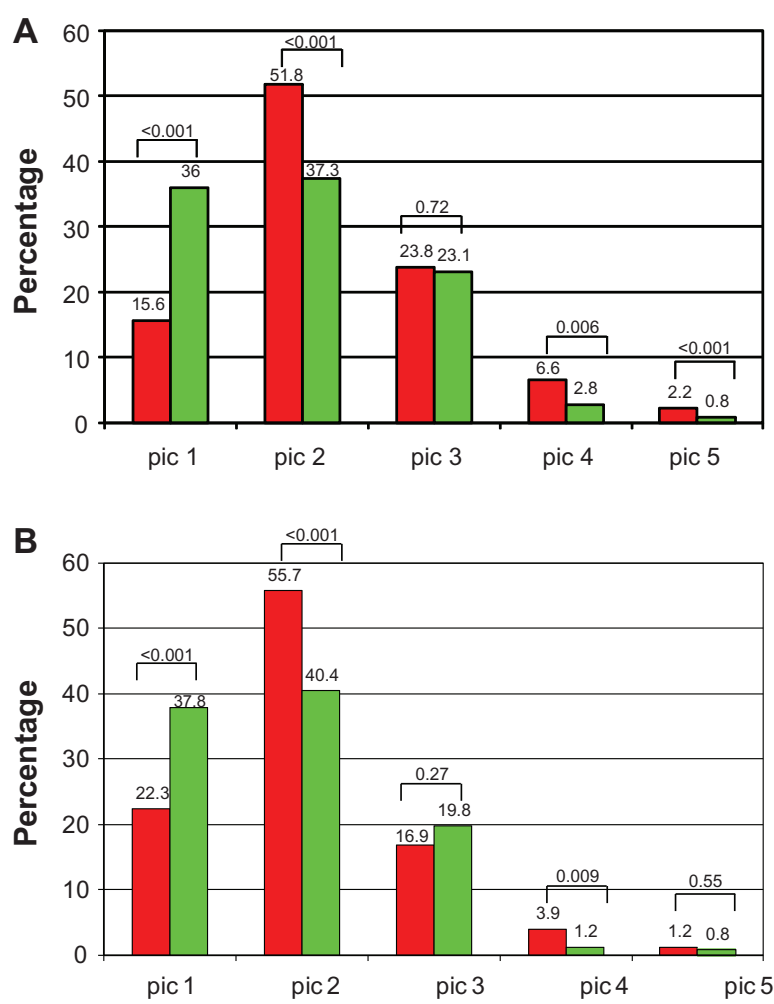

Figure 4 Preferences of patients aged $<40$ and $\geq 40$ years toward (A) female and (B) male pictures.

Notes: Red bar: aged $<40$ years. Green bar: aged $\geq 40$ years.

Abbreviation: Pic, picture.
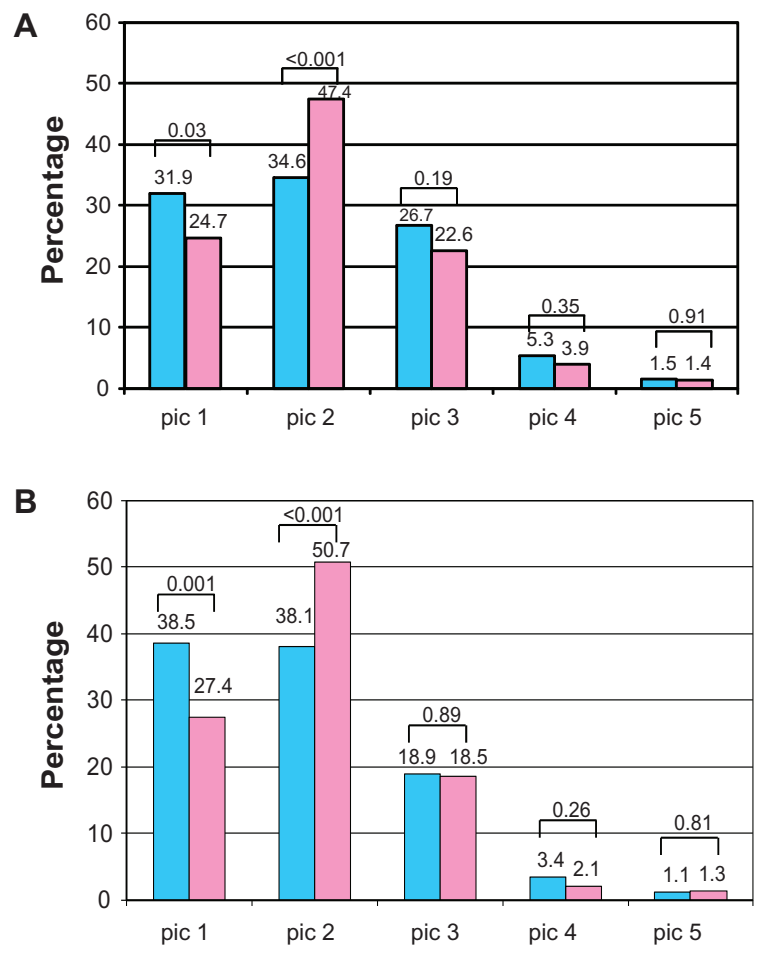

Figure 5 Preferences of female and male patients toward female (A and $\mathbf{B})$ male pictures.

Notes: Blue bar: males. Pink bar: females.

Abbreviation: Pic, picture.
Table 3 Logistic regression analysis of the association of pictures number I (professional attire) and number 2 (surgical scrubs) with potential explanatory factors

\begin{tabular}{|c|c|c|}
\hline $\begin{array}{l}\text { Pictures and } \\
\text { explanatory } \\
\text { variables }\end{array}$ & $\begin{array}{l}\text { Uni-variate } \\
\text { analysis OR } \\
(95 \% \mathrm{CI})\end{array}$ & $\begin{array}{l}\text { Multi-variate } \\
\text { analysis OR } \\
(95 \% \mathrm{Cl})\end{array}$ \\
\hline \multicolumn{3}{|l|}{ Picture I (female) } \\
\hline Gender (male) & $1.50(1.10,2.05)$ & $1.46(1.05,2.03)$ \\
\hline Age ( $\geq 40$ years) & $2.94(2.14,4.05)$ & $2.25(1.60,3.15)$ \\
\hline Medical department & $0.75(0.44,1.27)$ & - \\
\hline \multicolumn{2}{|l|}{ and university) } & $0.52(0.38,0.7 I)$ \\
\hline \multicolumn{3}{|l|}{ Picture 2 (female) } \\
\hline Gender (male) & $0.64(0.48,0.86)$ & $0.66(0.47,0.94)$ \\
\hline Age ( $\geq 40$ years) & $0.57(0.44,0.73)$ & $0.67(0.49,0.93)$ \\
\hline Medical department & I.64 $(0.97,2.77)$ & $1.38(0.80,2.38)$ \\
\hline High school & $1.69(1.29,2.21)$ & $1.65(1.19,2.29)$ \\
\hline \multicolumn{3}{|l|}{ and university } \\
\hline \multicolumn{3}{|l|}{ Picture I (male) } \\
\hline Gender (male) & I.78 (I.32, 2.40) & $1.93(1.35,2.75)$ \\
\hline Age ( $\geq 40$ years) & $1.96(1.46,2.62)$ & $1.66(1.16,2.38)$ \\
\hline Medical department & $1.02(0.59,1.75)$ & - \\
\hline High school & $0.56(0.42,0.74)$ & $0.59(0.42,0.84)$ \\
\hline \multicolumn{3}{|l|}{ and university } \\
\hline \multicolumn{3}{|l|}{ Picture 2 (male) } \\
\hline Gender (male) & $0.69(0.52,0.92)$ & $0.64(0.45,0.90)$ \\
\hline Age ( $\geq 40$ years) & $0.54(0.42,0.69)$ & $0.63(0.46,0.87)$ \\
\hline Medical department & I.16 (0.7I, I.89) & - \\
\hline High school & I.7I $(1.31,2.23)$ & $1.46(1.06,2.01)$ \\
\hline and university & & \\
\hline
\end{tabular}

Abbreviations: $\mathrm{OR}$, odds ratio; $\mathrm{Cl}$, confidence interval.

and female physicians. These results are important. Patients, given their illness, are often vulnerable and in a position of weakness with respect to their physician to whom they turn to for advice and cures. Physicians have a responsibility to put their patients at ease and a professional appearance may be part of that responsibility. If patients are uneasy with a physician's appearance, then the physician has a duty to consider changing his/her appearance. Essentially, the physician has a responsibility to act in their patients' interests (that, in some cases, may supersede their own individual beliefs, rights, or convenience).

Several limitations of our survey could be underlined; first of all, it does not take into consideration potential Italian regional cultural discrepancies (northern regions versus southern regions versus islands): it was a single center study performed on an island. Regional distinctions might be solved in the near future by conducting multicenter studies in different parts of Italy.

The cross-sectional nature of the study (ie, point estimates) is a methodological pitfall that does not allow analysis of the possibility that the preference would 
lead to a change in a long-term medical doctor-patient relationship; epidemiological longitudinal studies could address that issue.

Moreover, the age of physicians portrayed in the pictures may have been a confounding effect, influencing the choice of the respondents.

\section{Conclusion}

This study clearly indicates patients' needs for a sober professional image of their physician, deriving from a standard dress code and attention to detail in personal grooming (hair, nails, beard, weight, absence of jewelry, tattoos, piercing, etc). Patients prefer, and have come to expect, physicians to wear a white coat with a name tag and to dress conservatively, since this mode of dress conveys respect and gives formality to patient-physician interactions. The medical profession has a vested interest in maintaining this dress code, which, like the uniforms for the military and priests, affords professional identity, and the privilege and status that come with it. Status and privilege are accorded by society, but society requires that the medical profession uses these benefits in the interest of the patients they serve. Physicians engage in relationships with patients and all relationships require compromise. Dressing for the role does not cover up a lack of professionalism, but complements and completes it.

\section{Acknowledgments}

This work was supported by Clinica Medica and Epidemiology and Medical Statistics Unit, Department of Biomedical Sciences, University of Sassari, Sassari, Italy.

\section{Disclosure}

The authors report no conflict of interest in this work.

\section{References}

1. Jones WHS. Hippocrates. Volume 2. Cambridge, MA: Harvard University Press; 1923.

2. Gjerdingen DK, Simpson DE, Titus SL. Patients' and physicians' attitudes regarding the physician's professional appearance. Arch Intern Med. 1987;147:1209-1212.
3. Van Dulmen AM, Verhaak PFM, Bilo HJG. Shifts in doctor-patient communication during a series of outpatient consultations in noninsulin-dependent diabetes mellitus. Patient Educ Couns. 1997;30: 227-237.

4. Short D. First impression. Br J Hosp Med. 1993;50:270-271.

5. Rose A. Human Behavior and Social Process. Boston, MA: Houghton Mifflin Co; 1962.

6. Bersheild E, Gangested S. The social psychological implications of facial physical attractiveness. Clin Plast Surg. 1982;9:289-296.

7. Blumhagen DW. The doctor's white coat. Ann Inter Med. 1979;91: 111-116.

8. King LS. "Hey you!" and other forms of address. JAMA. 1985;254: 266-267.

9. Natkins LG. Hi, Lucille, this is Dr Gold! JAMA. 1982;247:2415.

10. Kriss JP. On white coats and other matters. New Engl J Med. 1975;292: 1024-1025.

11. Lynch PI. The physician's clothes. New Engl J Med. 1975;292:1270.

12. Rabson SM. Coats, white or soiled. New Engl J Med. 1975;293: $563-565$.

13. McKinstry B, Wang JX. Putting on the style: what patients think of the way their doctor dresses. Brit J Gen Pract. 1991;41:275-278.

14. Cha A, Hecht BR, Nelson K, Hopkins MP. Resident physician attire: does it make a difference to our patients? Am J Obstet Gynecol. 2004; 190:1484-1488.

15. Keenum AJ, Wallace LS, Stevens AR. Patients' attitudes regarding physical characteristics of family practice physicians. South Med J. 2003;96:1190-1194.

16. Major K, Hayase Y, Balderrama D, Lefor AT. Attitudes regarding surgeons' attire. Am J Surg. 2005;190:103-106.

17. Cousins N. How patients appraise physicians. N Engl J Med. 1985;313: $1422-1424$.

18. Anvik T. Doctors in a white coat - what do patients think and what do doctors do. Scand J Health Care. 1990;8:91-94.

19. Neinstein LS, Stewart S, Gordon N. Effect of physician dress styles on patient-physician relationship. J Adolesc Health Care. 1985;6: 456-459.

20. Manahem S, Shvartzman P. Is our appearance important to our patients? Fam Pract. 1998;15:391-397.

21. Ikusaka M, Kamegai M, Sunaga T, et al. Patients' attitude toward consultations by a physician without a white coat in Japan. Intern Med. 1999;38:533-536.

22. Fischer RL, Schaeffer K, Hunter RL. Attitudes of obstetrics and gynecology residents toward abortion participation: a Philadelphia area survey. Contraception. 2005;72:200-205.

23. Gherardi G, Cameron J, West A, Crossley M. Are we dressed to impress? A descriptive survey assessing patients' preference of doctors' attire in the hospital setting. Clin Med. 2009;9(6):519-524.

24. Lill MM, Wilkinson TJ. Judging a book by its cover: descriptive survey of patients' preferences for doctors' appearance and mode of address. BMJ. 2005;331:1524-1527.

25. Palazzo S, Hocken DB. Patients' perspectives on how doctors dress. J Hosp Infect. 2010;74:30-34.

26. LaSala KB, Nelson J. What contributes to professionalism? Medsurg Nurs. 2005;14:63-67.
Patient Preference and Adherence

\section{Publish your work in this journal}

Patient Preference and Adherence is an international, peer-reviewed, open access journal focusing on the growing importance of patient preference and adherence throughout the therapeutic continuum. Patient satisfaction, acceptability, quality of life, compliance, persistence and their role in developing new therapeutic modalities and compounds to

\section{Dovepress}

optimize clinical outcomes for existing disease states are major areas of interest. This journal has been accepted for indexing on PubMed Central. The manuscript management system is completely online and includes a very quick and fair peer-review system. Visit http://www.dovepress.com/ testimonials.php to read real quotes from published authors. 